\title{
Expressed motives of amateur karate and taekwondo athletes for sport participation
}

\author{
Nurullah Emir EKINCI, Halil BISGIN, Umit Dogan USTUN
}

School of Physical Education and Sports, University of Dumlupınar, Kütahya, Turkey.

Address correspondence to N. E. Ekinci, e-mail; nurullah.ekinci@dpu.edu.tr

\begin{abstract}
This study aimed to investigate amateur karate and taekwondo athletes' participation motivation mutually. A total of 206 amateur karate and taekwondo athletes voluntarily participated in the study. In the study to collect data Turkish version of Participation Motivation Questionnaire (PMQ) used. The questionnaire consisted of 30 items and eight factors. In the evaluation of data in addition to descriptive statistical methods, MANOVA was used to identify significant differences. As a result, according to descriptive statistics, while the most important motive for sport participation was found to be as "skills development," the least important motive was found to be as "friend" for both karate and taekwondo athletes. But MANOVA results did not reveal any significant differences (p>.05). This result is thought to be because of both karate and taekwondo are individual sport branches and requires both skill and talent.
\end{abstract}

Key words: Karate, participation motivation, sports, taekwondo.

\section{INTRODUCTION}

As a word motivation derives from the Latin word "movere" which has the meaning of "manipulation and activation" (17). Although motivation used in several means, it doesn't have an exact meaning because of it's' complexity, but simply we can describe motivation as "an internal condition which leads to the emergence of behaviors that shape human behavior" (18). Usually, two elements are used depending on motivation. First one is the movement or behavior of the individual to achieve the goals; the latter is the external factors which help the individual to perform. Motivation is related to hope and needs, goals, behavior and inform an individual about his or her performance (20).

According to Mouloud \& Abdelkader "motivation" is one of the key factors behind the behavior of the individuals (12). Furthermore, motivation can be considered as one of the most important variables in athletics because it can affect sports performance as well as the overall sports experience for an athlete (16).

As a term "participation motives" has traditionally been used in exercise psychology to refer to the reasons that individuals give for engaging in physical activity (10) and rooted from the basics of self-determination theory (5). In substance, selfdetermination theory handles motivation in three facets: (a) intrinsic motivation, (b) extrinsic motivation (divided into four groups as: integrated regulation, identified regulation, introjected regulation and external regulation) (c) amotivation. For example, in sport participation while independence and competence enforced by intrinsic motivation (11), future rewards or punishment enforced by extrinsic motivation (1) and when a person is intrinsically motivated, he/she will participate in the activity with more pleasure (15).

It is obvious that the relationship between motivation and sports is very important. As sports have psychological aspects, it is normal to be unsuccessful or failure in a situation in which there is no motivation. Also, every individual may have a reason or several reasons to take part in a sportive activity or to start a sports branch. In this paper we tried to identify participation motivation for amateur karate and taekwondo athletes. 


\section{MATERIALS \& METHODS}

\section{Study Design}

In the study, cross-sectional analytical method used as the study design. Researchers identified this method as one of the most commonly used methods in social and sport based studies. According to this method, first the data are obtained from a sampling group, than the relationships are identified and generalized back to the population (7).

\section{Research Sample}

Research sample consisted of 206 amateur karate and taekwondo athletes from İzmir province. The participants took part in the study voluntarily and were chosen in a random way.

\section{Data Gathering Tool}

As data gathering tool, Turkish version of Gill et al.' participation motivation questionnaire was used. The adaptation of the questionnaire for the Turkish culture first made by first Çelebi in 1993. But in 2001 Oyar et al. made another validity and reliability for the PMQ and revised the questionnaire. The study findings revealed a valid and reliable 30 item and eight factor scale (13). In this study we referenced Oyar et al. study (13).

\section{Analysis of the data}

In the evaluation of the data's first Cronbach's Alpha calculated for the scale as a means of reliability for the whole scale and dimensions. Then One Sample Kolmogorov-Smirnov test done to check the distribution of the data. According to results, data gathering tool was found reliable, and the data was normally distributed ( $>$.05). Lastly MANOVA was done at a significance level of $\alpha=0.05$ to determine the significant differences [(Box's $\mathrm{M}=11.973 ; \mathrm{p}=1.00$; $\mathrm{p}>$.05)] [Levene's test (df 1-204); $P$ (in the order) $.49, .98,36, .79$, $.53, .81, .84, .67 ; \mathrm{p}>.05)$.

\section{RESULTS}

Table 1 shows the mean and standard deviation of the subscale points for the participants. According to analyze results while skills development was the most important motive for both karate and taekwondo athletes, friend was the least important motive.

There was not a significant difference between amateur karate and taekwondo athletes when considered jointly on the variable participation motivation $\lambda .984 \mathrm{~F}(8-197)=.401, \mathrm{p}=.919$, partial $\mathrm{n}^{2}=$ .016. A separate ANOVA was conducted for each dependent variable at an alpha level of .006. There was no significant difference between amateur karate and taekwondo athletes on the dependent variables.

Table 1. Descriptive information on the motivations of the participants.

\begin{tabular}{lcccc}
\hline \multirow{2}{*}{ Variables } & \multicolumn{2}{c}{ Karate } & \multicolumn{2}{c}{ Taekwondo } \\
\cline { 2 - 5 } & Mean & SD & Mean & SD \\
\hline Success / Status & 2.66 & .34 & 2.58 & .36 \\
Physical Fitness & 2.69 & .36 & 2.68 & .36 \\
Team Spirit & 2.77 & .33 & 2.72 & .34 \\
Friend & 2.52 & .58 & 2.48 & .56 \\
Fun & 2.60 & .45 & 2.56 & .45 \\
Competition & 2.62 & .41 & 2.55 & .40 \\
Skills Development & 2.84 & .29 & 2.83 & .28 \\
Action / Being Active & 2.62 & .44 & 2.57 & .42 \\
\hline
\end{tabular}

Table 2. Sport participation motivation according to branch (MANOVA results).

\begin{tabular}{lccc}
\hline Variables & $\mathrm{F}$ & $\mathrm{p}$ & Partial Eta Squared \\
\hline Success / Status & 2.53 & .113 & .012 \\
Physical Fitness & .131 & .717 & .001 \\
Team Spirit & 1.061 & .304 & .005 \\
Friend & .235 & .628 & .001 \\
Fun & .331 & .566 & .002 \\
Competition & 1.474 & .226 & .007 \\
Skill Development & .006 & .938 & .000 \\
Action / Being Active & .681 & .410 & .003 \\
\hline
\end{tabular}

\section{DISCUSSION}

The aim of this study was to analyze expressed participation motives by amateur karate and taekwondo athletes mutually according to their branch. According to analyze results, it was found that although the most important motive for sports participation was "skills development" for both karate and taekwondo athletes, "friend" was the least important motive. Also there was no significant difference on participation motivation of the subjects. This result was thought to be a consequence of characteristic features of karate and taekwondo. Because both sport branches are individual sport branches and requires a great deal of skill and talent jointly. Similar to present findings, in his study on taekwondo athletes Korkutata found skills development as the most important motive and friend as the least important motive for sport participation (9). Furthermore, if we examine the literature we can see studies with parallel or different results with the current study. For example in their study on young athletes Altintas \& Bayar Koruc 
pointed out higher scores for sports participation in several factors such as skills development and team spirit in favor of team sport participants than individual sport participants (2). Furthermore, Bollok et al. indicated significant differences on participation motives of team sport participants on several factors and pointed out team sport participants were inspired to win over others, unlike those engaged in individual sports (3). In their study Pugh, et al., found that youth baseball players' participation motives were fun, self-improvement, and socializing with friends (14). And, in the literature studies indicated factors such as skills development, fun and friend are the key factors in sports participation $(4,19)$.

As a result, this study aimed to investigate participation motivation of amateur karate and taekwondo athletes' participation motivation mutually and a number of important results were obtained as a result of the study. Researchers stated that with the rapid urbanization and radical changes in the life style, people have less physical activity and participation in sport $(6,8)$. So, in order to avoid this decrease further research must be done on motivation patterns. Furthermore, strategies must be produced to keep alive the inlying motives for sport participation.

\section{REFERENCES}

1. Alexandris K, Tsorbatzoudis C, Grouios G. Perceived constraints on recreational sport participation: Investigating their relationship with intrinsic motivation, extrinsic motivation and amotivation. J Leisure Res, 2002; 34(3): 233-252.

2. Altıntaş A, Koruç PB. Determining participation motivation of young athletes with regard to gender and sport type. International Journal of Science Culture and Sport (IntJSCS), 2014; 2(5): 61-67.

3. Bollok S, Takacs J, Kalmar Z, Dobay B. External and internal sport motivations of young adults. Biomedical Human Kinetics, 2011; 3: 101-105.

4. Cerar K, Kondric M, Sindik J. The Profiling of University of Ljubljana students according to their motives for exercise participation. Zdr Varst, 2017; 56(2): 107-114.

5. Daniels MJ, Lawton LJ. Adolescent Aport Participants: Segmentation by Motivation Patterns. World Leisure Journal, 2003; 45(3): 35-42

6. Görgüt I, Güllü M. Examination of primary school handball player's reason for starting sport and life satisfactions. International Journal of Educational Sciences, 2016; 8(3): 83-96.
7. Gratton C, Jones I. Research Methods for Sports Studies. 2nd Edition, London: Routledge, 2010.

8. Jefferis BJ, Sartini C, Lee IM, Choi M, Amuzu A, Gutierrez C, Whincup PH. Adherence to physical activity guidelines in older adults, using objectively measured physical activity in a population based study. BMC Public Health, 2015; 14: 382-396.

9. Korkutata A. Participation motivation in sport: A study on taekwondo athletes. Turkish Journal of Sport and Exercise, 2016; 18(3): 47-55.

10. Markland D, Ingledew L. Exercise Participation Motives: A Self Determination Theory Perspective. In Martin S. Hagger, Nikos L.D. Chatzisarantis (Eds), Intrinsic Motivation and SelfDetermination in Exercise and Sport (pp: 25-29). 1ed. Champaign: Human Kinetics, 2007.

11. Mishra M, Acharya A. Relationships between motivation type and sport participation among Indian students. International Journal of Physical Education, Sports and Health, 2017; 4(3): 57.

12. Mouloud K, Abdelkader A. Motives to practice physical education and sports activities among pupils of the final sections of secondary education. International Journal of Sport Studies, 2015; 5(10): 1149-1154.

13. Oyar ZB, Aşçı FH, Çelebi M, Mülazımoğlu Ö. Validitv and reliability of "Participation Motivation Questionnaire. Hacettepe University J Sport Sciences, 2001; 12(2): 21-23.

14. Pugh SF, Wolff R, DeFrancesco C, Gilley W, Heitman RJ. A case study of elite male youth baseball athletes' perception of the youth sports experience. Education, 2000; 120(4): 773-778.

15. Recours RA, Souville N, Griffet J. Expessed motives for informal and club association-based sports participation. J. Leisure Res, 2004; 36: 1-22.

16. Shelley LH, Steven FP, Neil AS. Achievement Motivation of Collegiate Athletes for Sport Participation. International Journal of Sports Science, 2017; 7(2): 25-28.

17. Ustun UD, Kalkavan A, Demirel M. Investigating free time motivation scores of physical education and faculty of education students according to different variables. The Online Journal of Recreation and Sport, 2013; 2(1): 18-26.

18. Uysal M, Hagan LAR. Motivation for Pleasure Travel. In Khan MA, Olsen MD, Var T. (Eds), VNR's Encylopedia of Hospitality and Tourism (pp: 798-810). New York: Van Nostrand Reinhold, 1993.

19. White AS, Duda LJ. The relationship of gender, level of sport involvement, and participation motivation to task and ego orientation. International Journal of Sport Psychology, 1994; 25: $40-48$.

20. Yalçın İ, Çalık F, Ramazanoğlu F, Tutar ÖF. Research on the achievement motivation levels of the amateur football players. SHS Web of Conferences, 37, 2017. 